\title{
Midterm, multicenter clinical and hemodynamic results for the Trifecta aortic pericardial valve
}

\author{
Scott Goldman, MD, ${ }^{\mathrm{a}}$ Anson Cheung, MD, ${ }^{\mathrm{b}}$ Joseph E. Bavaria, MD, ${ }^{\mathrm{c}}$ Michael R. Petracek, MD, ${ }^{\mathrm{d}}$ \\ Mark A. Groh, MD, and Hartzell V. Schaff, MD
}

\section{ABSTRACT}

Objective: To evaluate the midterm hemodynamic performance and clinical outcomes of the Trifecta aortic pericardial valve.

Methods: In a multicenter, prospective, nonrandomized, follow-up study, 710 patients underwent surgical implantation of a pericardial stented aortic prosthesis (Trifecta valve; St Jude Medical, St. Paul, Minn). The valve is constructed from bovine pericardium mounted externally onto a titanium stent. Subjects were followed on an annual basis over 6 years.

Results: Operations were performed from 2007 to 2009, and mean age was $72.4 \pm 9.3$ years; 471 of $710(66.3 \%)$ were men. Preoperatively, 361 of 710 $(50.8 \%)$ of patients were in New York Heart Association class III or IV, and at 6 years postoperatively, 92 of $96(95.8 \%)$ were New York Heart Association class I or II. Six years postoperatively, average mean gradient across all valve sizes was $11.0 \mathrm{~mm} \mathrm{Hg}$, and the average effective orifice area index was $0.80 \mathrm{~cm}^{2} / \mathrm{m}^{2}$. The proportion of patients without moderate-to-severe valvular regurgitation at 6 years was $95.2 \%$ (80/84). Six years postoperatively, freedom from valve-related mortality, nonstructural dysfunction, and paravalvular leak were $98.3 \%$, $98.6 \%$, and $98.9 \%$, respectively, and freedom from reoperation due to structural valve deterioration was $97.3 \%$ (95\% confidence limits, 98.6-94.7).

Conclusion: These midterm results demonstrate that the Trifecta valve is a safe and effective valve substitute with excellent hemodynamic performance and durability that is maintained through the 6-year follow-up period. (J Thorac Cardiovasc Surg 2017;153:561-9)

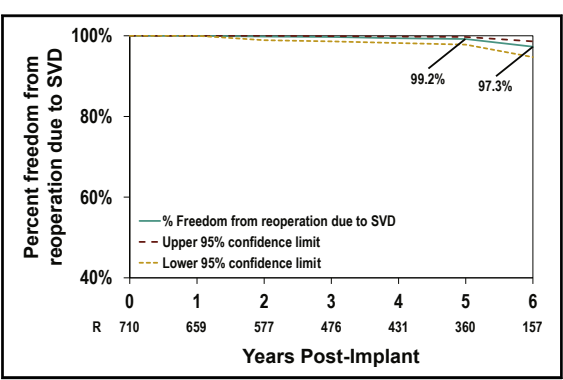

Freedom from reoperation due to structural valve deterioration was $97.3 \%$ at 6 years.

\section{Central Message}

Excellent hemodynamic performance and durability was maintained through 6 years of follow-up.

\section{Perspective}

Use of bioprosthetic aortic heart valves has steadily increased in recent years. The availability of a bioprosthetic aortic heart valve that has excellent hemodynamic performance and durability is particularly attractive when encountering a small aortic annulus.

See Editorial Commentary page 570.

\footnotetext{
From ${ }^{a}$ Lankenau Heart Group, Lankenau Hospital, Wynnewood, Pa; ${ }^{b}$ Division of Cardiovascular Surgery, St Paul's Hospital - University of British Columbia, Vancouver, British Columbia, Canada; ${ }^{\mathrm{c} D i v i s i o n}$ of Cardiovascular Surgery, Hospital of the University of Pennsylvania, Philadelphia, $\mathrm{Pa}$; ${ }^{\mathrm{d}}$ Department of Cardiac Surgery, Vanderbilt University Medical Center, Nashville, Tenn; ${ }^{\mathrm{e}}$ Asheville Heart, Mission Health and Hospitals, Asheville, NC; and ${ }^{\mathrm{f}}$ Division of Cardiovascular Surgery, Mayo Clinic, Rochester, Minn.

This study was sponsored by St Jude Medical, who was responsible for collecting and analyzing the data and for collaborating with the investigators regarding the preparation and submission of this manuscript. The authors had freedom to explore the data with final authority to submit the manuscript for publication. The manuscript was drafted by the authors with assistance provided by Dan Gutfinger, MD (see Acknowledgements), who had full access to the data.

ClinicalTrials.gov Registration Numbers: NCT00475709, NCT01514162, and NCT01593917.

Read at the 96th Annual Meeting of The American Association for Thoracic Surgery, May 14-18, 2016, Baltimore, Maryland.

Received for publication April 15, 2016; revisions received Sept 9, 2016; accepted for publication Sept 28, 2016; available ahead of print Dec 10, 2016.

Address for reprints: Scott Goldman, MD, Lankenau Hospital, 100 East Lancaster Ave, Wynnewood, PA 19096 (E-mail: GoldmanS@mlhs.org).

$0022-5223$

Copyright (C) 2016 by The American Association for Thoracic Surgery. Published by Elsevier Inc. This is an open access article under the CC BY-NC-ND license (http:// creativecommons.org/licenses/by-nc-nd/4.0/).

http://dx.doi.org/10.1016/j.jtcvs.2016.09.089
}

The use of bioprosthetic aortic heart valves has increased steadily in recent years as a result of increasing numbers of elderly patients undergoing aortic valve replacement, as well as anticipated improved durability of pericardial prostheses. ${ }^{1}$ The availability of a bioprosthetic aortic heart valve with excellent hemodynamic performance and durability is attractive particularly for younger patients and those with a small aortic root. By incorporating experience from previous valve designs and leveraging improvements in tissue processing, the Trifecta aortic pericardial valve (St Jude Medical, St. Paul, Minn) was

Scanning this QR code will take you to the supplemental figures, tables, video, and appendices. To view the AATS 2016 Webcast, see the URL next to the video thumbnail. 


\section{Abbreviations and Acronyms \\ NYHA $=$ New York Heart Association \\ SVD = structural valve deterioration \\ TAVR $=$ transcatheter aortic valve replacement}

introduced into commercial use in 2010. Mid-term results on the safety and performance of the valve are reported based on a cohort of patients from the premarket approval study who consented to participate in longerterm follow-up.

\section{MATERIALS AND METHODS Study Design}

To evaluate the mid-term clinical outcomes of the Trifecta valve, 710 eligible patients from 11 investigational sites were followed in this multicenter, prospective, nonrandomized, observational study. Valves were implanted with the use of standard methods (Video 1) between 2007 and 2009 as part of the premarket approval study (ClinicalTrials.gov number, NCT00475709) with inclusion/exclusion criteria as previously described (Appendix E1). ${ }^{2}$ The 11 participating institutions consist of 9 investigational sites in the United States and 2 sites in Canada (Appendix E2). At each site, there were 2 or more primary surgeons who performed implants. After the premarket study was closed, 434 patients at these 11 sites moved on to participate in either a postapproval study $(n=245)$ mandated by the Food and Drug Administration or a voluntary postmarket long-term follow-up study $(\mathrm{n}=189)$. The postapproval and long-term follow-up studies were both sponsored by St Jude Medical and registered with ClinicalTrials.gov, NCT01514162 and NCT01593917 (Figure E1). The appropriate institutional review board approval was obtained at each center, and all patients gave written informed consent to participate in each study.

The Trifecta valve is a trileaflet stented pericardial valve designed for supra-annular placement in the aortic position. The valve is fabricated via a polyester-covered titanium stent. The stent, excluding the sewing cuff, is then covered with porcine pericardial tissue. This covering is designed to provide protection from mechanical wear by allowing only tissue-to-tissue contact during valve function. A silicone insert in the polyester sewing cuff is contoured slightly to conform to the shape of the native annulus. The valve leaflets are fabricated from bovine pericardium.

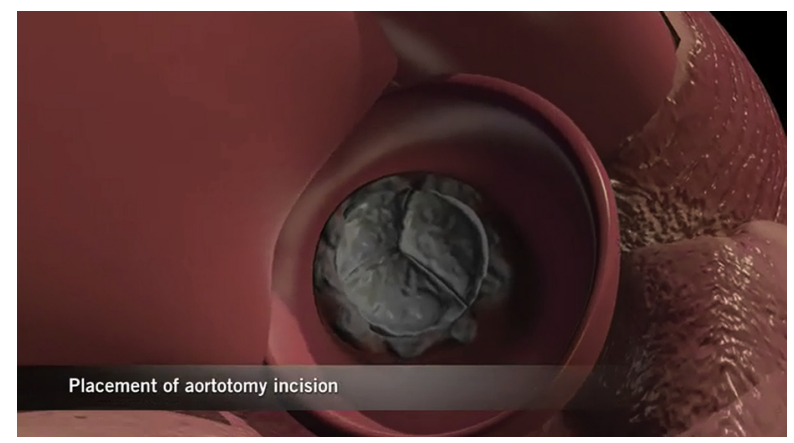

VIDEO 1. Surgical implant procedure of a 71-year-old woman who underwent isolated aortic valve replacement with a 21-mm Trifecta valve as part of the premarket approval study with subsequent follow-up in the postapproval study. Echocardiogram performed at 5 years after implant shows no aortic regurgitation, a mean gradient of $9.6 \mathrm{~mm} \mathrm{Hg}$, and an effective orifice area index of $0.85 \mathrm{~cm}^{2} / \mathrm{m}^{2}$. Video available at: http://www.jtcvsonline.org/ article/S0022-5223(16)31598-7/addons.
The porcine and bovine pericardium are preserved and cross-linked in glutaraldehyde. Glutaraldehyde, formaldehyde and ethanol are used in the valve sterilization process. In addition, the Trifecta valve is processed with an ethanol-based anticalcification treatment (Linx AC; St Jude Medical) that in animal studies has demonstrated resistance to calcification. ${ }^{3}$ There are no clinical data currently available that evaluate the long-term impact of the anticalcification tissue treatment in humans.

In the premarket approval study, the instructions for use recommended a postoperative antithrombotic regimen consisting of long-term, low-dose aspirin, unless contraindicated. A recommendation also is made for long-term anticoagulation therapy, unless contraindicated, in patients with risk factors for thromboembolism.

\section{Follow-up}

In the premarket approval study (NCT00475709) follow-up occurred at hospital discharge and during clinic visits at 6 months and at each year postimplant until study closure. Patients in the postapproval study (NCT01514162) continued to be followed on an annual basis with a clinic visit, whereas patients in the long-term follow-up study (NCT01593917) were followed annually with a clinic visit except for years 4 and 6 , when a telephone follow-up was performed. Each clinic visit consisted of a transthoracic echocardiogram and assessments for New York Heart Association (NYHA) functional classification, serious adverse events, and general clinical status. An independent core laboratory assessed all echocardiograms, and an independent clinical events committee adjudicated adverse events. Over an interval of 6 years, 701 patients underwent 3751 clinic visits with a total of 3698 echocardiograms $(98.6 \%)$ performed. The proportion of echocardiograms to clinic visits were 691 of $701(98.6 \%)$ at discharge, 659 of $663(99.4 \%)$ at 6 months, 648 of $650(99.7 \%)$ at Year 1, 588 of $594(99.0 \%)$ at Year 2, 448 of $450(99.6 \%)$ at Year 3, 219 of 222 $(98.6 \%)$ at Year 4, 358 of $369(97.0 \%)$ at Year 5, and 87 of 102 $(85.3 \%)$ at Year 6. Adverse events were classified according to the standardized definitions from The American Association for Thoracic Surgery and the Society of Thoracic Surgeons. ${ }^{4}$ Events were classified as occurring early (within 30 days of implant) or late ( $\geq 31$ days after implant).

\section{Statistical Analysis}

Statistical analyses were performed with SAS software version 9.3 (SAS institute Inc, Cary, NC). Continuous variables are presented as mean \pm standard deviation and range (minimum, maximum) and categorical variables as frequencies and percentages. For late adverse events, KaplanMeier analyses were used to summarize the time to first adverse events. Linear mixed models (SAS PROC MIXED) were used to evaluate the change over time of the hemodynamic measurements. ${ }^{5-7}$ As part of this evaluation, the skewed hemodynamic measurements of aortic valve gradient, effective orifice area, and effective orifice area index were transformed logarithmically to achieve a more normal distribution of dependent variables. The models also include a transformation of implant duration and valve size as fixed effects, along with a random intercept and a random slope for the implant duration (Table E1). Ordinal longitudinal mixed models (SAS PROC NLMIXED) were used to evaluate the change over time of the ordinal repeated measures of NYHA class and aortic regurgitation grade. The ordinal longitudinal mixed models include the continuous variable of implant duration as a fixed effect and a random intercept (Table E2).

\section{RESULTS}

The mean age of the 710 patients was $72.4 \pm 9.3$ years, with 152 patients $(21.4 \%)$ having an age $\geq 80$ years. Baseline patient demographics and operative details for these patients are detailed in Table 1 and Table 2. Indications for aortic valve replacement included stenosis in 366 patients $(51.6 \%)$, regurgitation in 45 patients $(6.3 \%)$, and mixed 
TABLE 1. Patient demographics

\begin{tabular}{lc}
\hline \multicolumn{1}{c}{ Variable } & $\mathbf{N}=\mathbf{7 1 0}$ \\
\hline Age at implant, y & $72.4 \pm 9.3(710)(33,95)$ \\
Subject sex, male & $66.3 \%(471 / 710)$ \\
Body mass index, kg/m ${ }^{2}$ & $29.3 \pm 5.4(710)(15.3,49.1)$ \\
Medical history & \\
Hypertension & $81.0 \%(575 / 710)$ \\
Hyperlipidemia & $73.5 \%(522 / 710)$ \\
Diabetes & $25.6 \%(182 / 710)$ \\
Smoking history (previous or current) & $57.7 \%(410 / 710)$ \\
Coronary artery disease & $60.6 \%(430 / 710)$ \\
Peripheral vascular disease & $10.7 \%(76 / 710)$ \\
Kidney disease & $7.7 \%(55 / 710)$ \\
Low ejection fraction $(<50 \%)$ & $13.5 \%(96 / 710)$ \\
Atrial fibrillation/flutter & $16.9 \%(120 / 710)$ \\
Chronic oral anticoagulation therapy & $11.0 \%(78 / 710)$ \\
Hemorrhage, excessive bleeding & $5.1 \%(36 / 710)$ \\
Carotid artery disease & $24.2 \%(172 / 710)$ \\
TIA & $7.7 \%(55 / 710)$ \\
Stroke, cerebrovascular accident, & $6.2 \%(44 / 710)$ \\
$\quad$ or RIND &
\end{tabular}

Continuous variables are presented as mean \pm standard deviation and range (minimum, maximum) and categorical variables as percentages and frequencies. TIA, Transient ischemic attack; RIND, reversible ischemic neurologic deficit; NYHA, New York Heart Association.

pathology in 299 patients $(42.1 \%)$. Eleven patients $(1.5 \%)$ underwent replacement of a prosthetic aortic valve or an aortic homograft, whereas the remainder of patients underwent replacement of the native aortic valve. Smaller valve sizes $(19 \mathrm{~mm}$ and $21 \mathrm{~mm})$ were implanted in $38.7 \%$ of patients $(\mathrm{n}=275)$. Concomitant procedures were performed in $58.2 \%$ (413/710), with coronary artery bypass grafting being the most frequent concomitant procedure at $37.3 \%$ (265/710). NYHA class III or IV heart failure was present
TABLE 2. Operative details

\begin{tabular}{lc}
\hline \multicolumn{1}{c}{ Variable } & $\mathbf{N}=\mathbf{7 1 0}$ \\
\hline Implanted valve size, mm & \\
19 & $11.1 \%(79 / 710)$ \\
21 & $27.6 \%(196 / 710)$ \\
23 & $33.1 \%(235 / 710)$ \\
25 & $21.4 \%(152 / 710)$ \\
27 & $5.4 \%(38 / 710)$ \\
29 & $1.4 \%(10 / 710)$ \\
Aortic crossclamp time, min & \\
All subjects & $84.1 \pm 36.1(710)(19,255)$ \\
With concomitant procedure & $97.7 \pm 36.7(413)(21,255)$ \\
Without concomitant procedure & $65.1 \pm 25(297)(19,181)$ \\
Cardiopulmonary bypass time (min) & \\
All subjects & $112.1 \pm 49.1(710)(25,334)$ \\
With concomitant procedure & $130 \pm 49.9(413)(35,334)$ \\
Without concomitant procedure & $87.2 \pm 35.2(297)(25,243)$ \\
Concomitant procedures & \\
None (AVR alone) & $41.8 \%(297 / 710)$ \\
Coronary artery bypass grafting & $37.3 \%(265 / 710)$ \\
Mitral valve repair & $3.7 \%(26 / 710)$ \\
Tricuspid valve repair & $2.1 \%(15 / 710)$ \\
Maze or cardiac ablation & $5.9 \%(42 / 710)$ \\
Atrial septal defect & $4.6 \%(33 / 710)$ \\
Root enlargement & $2.0 \%(14 / 710)$ \\
\hline Co & \\
\hline
\end{tabular}

Continuous variables are presented as mean \pm standard deviation and range (minimum, maximum) and categorical variables as percentages and frequencies. $A V R$, Aortic valve replacement.

preoperatively in $50.8 \%(361 / 710)$. The median patient follow-up was 5.0 years (interquartile range, 2.1-6.0), and the total duration of follow-up was 2873.4 late patient-years.

\section{NYHA Classification}

The trend of NYHA functional classification over time is shown in Figure 1. At 6 years of clinical follow-up, $90.6 \%$ of patients were NYHA class I. A further $5.2 \%$ of patients were

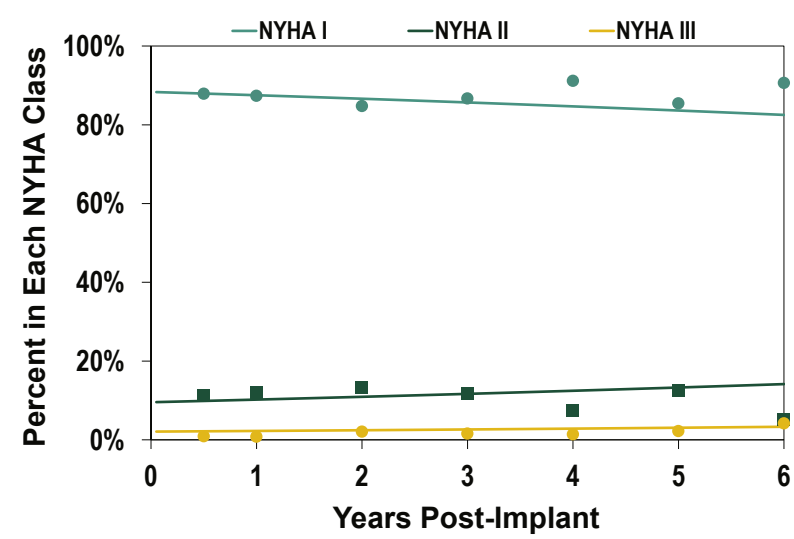

FIGURE 1. Evolution of NYHA functional classification over time. Symbols represent the observed percentages of patients in each NYHA class over time. Solid lines represent the solution for an ordinal logistic longitudinal repeat-measures model with only implant duration as a variable. NYHA, New York Heart Association 
NYHA class II, and $4.2 \%$ of patients were NYHA class III. There were no instances of NYHA class IV in follow-up. At 6 years, the observed proportion of patients without NYHA class III or IV symptoms was $95.8 \%(92 / 96)$.

\section{Hemodynamic Performance}

The hemodynamic results over time for each valve size are presented in Figure 2. Across all valve sizes the aortic valve gradient increased from $7.7 \pm 3.3 \mathrm{~mm} \mathrm{Hg}$ at 1 year to $9.1 \pm 4.8 \mathrm{~mm} \mathrm{Hg}$ at 3 years and to $11.0 \pm 6.3 \mathrm{~mm} \mathrm{Hg}$ at 6 years postimplant. The effective orifice area decreased from $1.74 \pm 0.37 \mathrm{~cm}^{2}$ at 1 year to $1.61 \pm 0.37 \mathrm{~cm}^{2}$ at 3 years and to $1.59 \pm 0.37 \mathrm{~cm}^{2}$ at 6 years postimplant. The effective orifice area index decreased from $0.88 \pm 0.17 \mathrm{~cm}^{2} / \mathrm{m}^{2}$ at 1 year to $0.82 \pm 0.17 \mathrm{~cm}^{2} / \mathrm{m}^{2}$ at 3 years and to $0.80 \pm 0.19 \mathrm{~cm}^{2} / \mathrm{m}^{2}$ at 6 years postimplant. Moderate or severe aortic regurgitation increased from an observed rate of $1.6 \%$ at 1 year to $2.9 \%$ at 3 years and to $4.8 \%$ at 6 years postimplant. The observed proportion of patients without moderate or severe aortic regurgitation at 6 years was $95.2 \%(80 / 84)$.

\section{Clinical Outcomes}

Kaplan-Meier analysis of freedom from all-cause mortality is presented in Figure 3. Early ( $\leq 30$ days postimplant) mortality occurred in 11 patients $(1.5 \%)$, and there were 57 late ( $\geq 31$ days) deaths, yielding a linearized mortality rate of $1.98 \%$ per late patient-year. At 3 years, cumulative freedom from overall mortality was $93.0 \%$, and freedom from valve-related mortality was $99.2 \%$. The same measures at 6 years (157 patients at risk) were $87.9 \%$ and $98.3 \%$, respectively.

Clinical outcomes after aortic valve replacement are shown in Table 3 . There were $52(7.3 \%)$ instances of early major bleeding, of which $39(5.5 \%)$ were from mediastinal or thoracic sites with $27(3.8 \%)$ requiring surgical intervention. At 1 year, 3 years, and 6 years postimplant, freedom from all major bleeding events was $91.7 \%$, $89.3 \%$, and $83.5 \%$, respectively. Among the 51 patients with late bleeding events, 20 patients $(39.2 \%)$ were receiving anticoagulation at the time of the event. There were no episodes of valve thrombosis or clinically significant hemolysis throughout follow-up.

Preoperatively, $16.9 \%$ of patients had a history of atrial fibrillation/flutter, with $11.0 \%$ of patients being on chronic oral anticoagulation therapy. The predominant underlying rhythm before aortic valve replacement was atrial fibrillation/flutter in $8.5 \%$ (60/710). New-onset atrial fibrillation requiring postoperative treatment occurred in $36.6 \%$ (238/650). New permanent pacemakers were
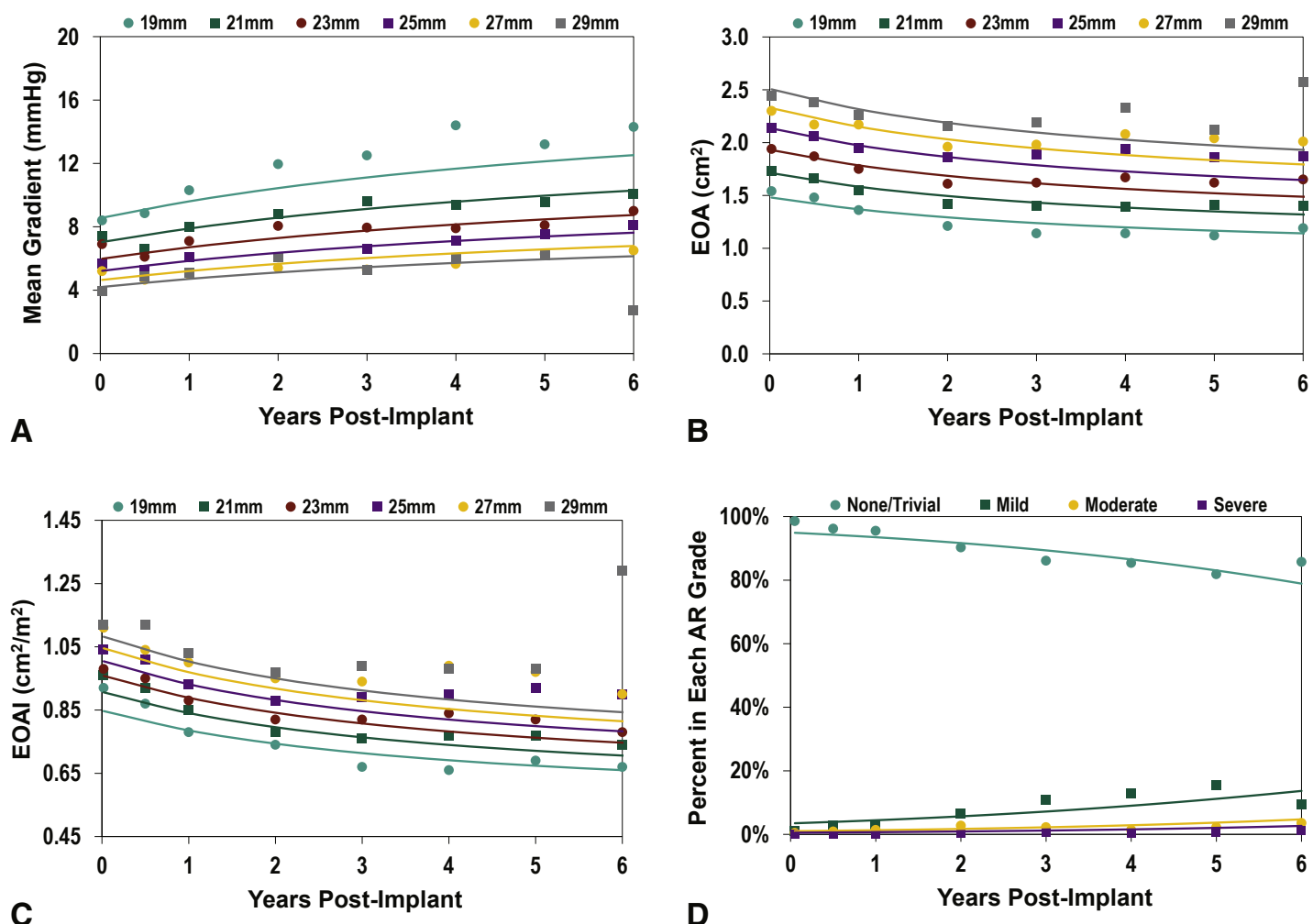

FIGURE 2. A, Evolution of mean transvalvular gradient over time. B, Evolution of EOA over time. C, Evolution of EOAI over time. D, Evolution of AR over time. Symbols represent median values by valve size at each follow-up (A, B, and C), or the percentage of patients in each AR grade (D). Solid lines represent by valve size linear mixed model estimates over time (A, B, and C), or the solution for an ordinal logistic longitudinal repeat-measures model with only implant duration as a variable. EOA, Effective orifice area; EOAI, effective orifice area index; $A R$, aortic regurgitation. 


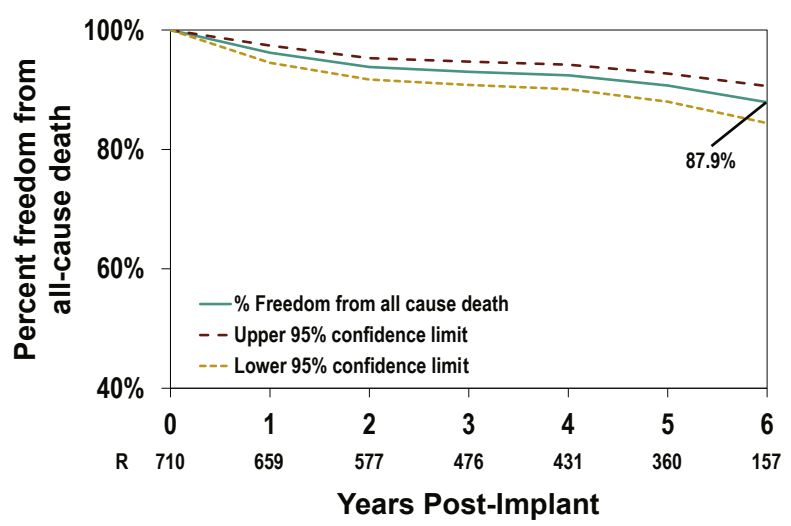

FIGURE 3. Kaplan-Meier analysis of freedom from all-cause mortality.

implanted within 30 days postoperatively in 43 patients (6.1\%), which include 5 patients with a history of atrial fibrillation who underwent a concomitant maze or ablation procedure. At hospital discharge, oral anticoagulation therapy consisting of warfarin was prescribed to $22.5 \%$ (158/701) of patients, which was decreased to $16.6 \%$ $(110 / 662)$ at 6 months after aortic valve replacement. Eighty-five percent of the patients $(n=134)$ being discharged on oral anticoagulation therapy were being treated for atrial fibrillation. In the remainder of patients discharged on oral anticoagulation therapy $(n=24$; $15 \%$ ), the indication for anticoagulation therapy was not specified; however, in 8 of these patients, oral anticoagulation therapy was already prescribed preoperatively. Among patients who were not discharged on oral anticoagulation therapy, $96.3 \%(523 / 543)$ were discharged on either aspirin or another antiplatelet agent.

Freedom from all embolic events was 96.0\%, 94.6\%, and $93.5 \%$ at 1 year, 3 years, and 6 years postimplant, respectively. Freedom from nonstructural dysfunction and paravalvular leak at 6 years was $98.6 \%$ and $98.9 \%$, respectively. Freedom from endocarditis was $99.4 \%$, $99.3 \%$, and $98.9 \%$ at 1 year, 3 years, and 6 years postimplant, respectively.

There was one explant that occurred 1 day after implant as a result of a suture injury to a congenitally malpositioned intramural coronary artery. At the time of valve explant, there was no evidence of valve malfunction, and it was determined that the coronary artery was not obstructed by the prosthesis.

\section{Durability}

There were a total of 18 reoperations resulting in valve explant that occurred beyond 30 days postimplant. There were no cases of valve repair or transcatheter valve-in-valve procedures performed in any of the patients. The explants were attributable to endocarditis $(\mathrm{n}=3)$, nonstructural valve dysfunction $(\mathrm{n}=4)$, and structural valve deterioration (SVD; $\mathrm{n}=11$ ). Freedom from reoperation was $99.4 \%, 98.6 \%$, and $96.0 \%$ at 1 year, 3 years, and 6 years postimplant, respectively. Kaplan-

TABLE 3. Clinical outcomes

\begin{tabular}{|c|c|c|c|c|c|}
\hline \multirow[b]{2}{*}{ Adverse event } & \multirow[b]{2}{*}{ Early events, no. $(\%)(\mathbf{N}=\mathbf{7 1 0})$} & \multirow[b]{2}{*}{ Late events, no. } & \multicolumn{3}{|c|}{$\%$ Freedom $*(95 \%$ CI $)$} \\
\hline & & & $1 \mathbf{y}$ & $3 \mathbf{y}$ & $6 y$ \\
\hline Embolism & $20(2.8)$ & 25 & $96.0(94.2-97.2)$ & $94.6(92.6-96.1)$ & $93.5(91.1-95.3)$ \\
\hline Neurologic & $18(2.5)$ & 24 & - & - & - \\
\hline TIA & $2(0.3)$ & 12 & - & - & - \\
\hline RIND & $10(1.4)$ & 3 & - & - & - \\
\hline Stroke & $6(0.8)$ & 9 & - & - & - \\
\hline Retinal & $1(0.1)$ & 1 & - & - & - \\
\hline Mesenteric & $1(0.1)$ & 0 & - & - & - \\
\hline Thrombosis & $0(0.0)$ & 0 & 100 & 100 & 100 \\
\hline Major bleed & $52(7.3)$ & 51 & $91.7(89.5-93.6)$ & $89.3(86.7-91.4)$ & $83.5(79.7-86.6)$ \\
\hline Mediastinal or thoracic bleed & $39(5.5)$ & 3 & - & - & - \\
\hline Requiring surgical intervention & $27(3.8)$ & 1 & - & - & - \\
\hline Gastrointestinal bleed & $9(1.3)$ & 28 & - & - & - \\
\hline Permanent pacemaker implant & $43(6.1)$ & 11 & $93.3(91.2-95.0)$ & $92.4(90.1-94.2)$ & $92.2(89.8-94.0)$ \\
\hline Endocarditis & $0(0.0)$ & 6 & $99.4(98.5-99.8)$ & $99.3(98.2-99.7)$ & $98.9(97.2-99.5)$ \\
\hline Structural deterioration & $0(0.0)$ & 15 & 100 & $99.7(98.6-99.9)$ & $95.7(92.6-97.5)$ \\
\hline Nonstructural dysfunction & $1(0.1)$ & 7 & $99.6(98.7-99.9)$ & $98.9(97.6-99.5)$ & $98.6(97.0-99.3)$ \\
\hline Paravalvular leak & $1(0.1)$ & 5 & 99.7 (98.9-99.9) & $99.2(98.1-99.7)$ & $98.9(97.4-99.5)$ \\
\hline Reoperation & $1(0.1)$ & 18 & $99.4(98.5-99.8)$ & $98.6(97.3-99.3)$ & $96.0(93.4-97.6)$ \\
\hline Due to SVD & $0(0.0)$ & 11 & 100 & $99.7(98.6-99.9)$ & $97.3(94.7-98.6)$ \\
\hline Mortality & $11(1.5)$ & 57 & $96.2(94.5-97.4)$ & $93.0(90.8-94.7)$ & $87.9(84.4-90.6)$ \\
\hline Valve-related & $1(0.1)$ & 6 & $99.7(98.9-99.9)$ & $99.2(98.2-99.7)$ & $98.3(96.1-99.3)$ \\
\hline
\end{tabular}

$C I$, Confidence interval; TIA, transient ischemic attack; RIND, reversible ischemic neurologic deficit; $S V D$, structural valve deterioration. *Kaplan-Meier analysis of freedom from first occurrence of each event with $95 \%$ CI. 
Meier analysis of freedom from reoperation due to SVD is presented in Figure 4. Among the 11 cases of SVD calcification or fibrous thickening of the leaflets was present in 10 of the cases, and a noncalcific leaflet tear was present in 1 case. The noncalcific leaflet tear occurred in a younger patient (age 49 years) who had a native bicuspid aortic valve. Reoperations due to SVD were for valve sizes $21 \mathrm{~mm}$ (3 valves), $23 \mathrm{~mm}$ (4 valves), and $25 \mathrm{~mm}$ (4 valves). Patients who underwent reoperation due to SVD were $64.1 \pm 11.8$ years of age, with none of these patients having renal failure. When limiting the analysis to patients with an age $\geq 65$ years, the freedom from reoperation due to SVD was $98.3 \%$ at 6 years of follow-up. When we included all patients with SVD (15 total with or without reoperation), the freedom from SVD was $95.7 \%$ at 6 years. Freedom from reoperation due to SVD in patients with an age $<65$ years was $93.8 \%$ at 6 years of follow-up.

\section{DISCUSSION}

This prospective, multicenter follow-up study demonstrates that aortic valve replacement with the Trifecta valve is associated with excellent hemodynamic performance and satisfactory durability through 6 years of follow-up. An association between hemodynamic performance and durability was evaluated recently in a large, single-center study involving a pericardial tissue heart valve. ${ }^{8}$ Valves that had a greater postoperative transvalvular gradient and that demonstrate a more rapid increase in transvalvular gradients were more likely to develop SVD over time. A gradual increase in the transvalvular gradient of 0.5 to $1 \mathrm{~mm} \mathrm{Hg}$ per year is a normal finding during the initial 10 years after implantation of a bioprosthetic heart valve, and is considered not clinically significant. ${ }^{9}$ In the absence of anticalcification treatment or when the valve is implanted in younger patients or patients with renal failure, however, the increase in transvalvular gradient may become more

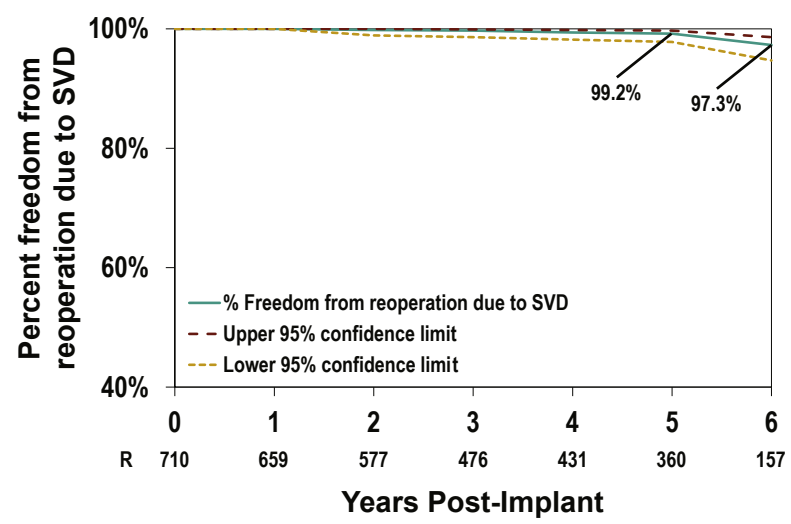

FIGURE 4. Kaplan-Meier analysis of freedom from reoperation due to SVD. SVD, Structural valve deterioration. rapid $(>2 \mathrm{~mm} \mathrm{Hg} / \mathrm{y})$ with an increased likelihood of developing SVD. ${ }^{10,11}$ Mechanisms responsible for the postoperative increase in transvalvular gradient may include an immunological reaction with deposition of platelets and subsequent formation of a fibrin layer with thickening of the leaflets. Excessive formation of pannus also may contribute to the process by restricting leaflet motion. In some cases, this biological reaction may progress to leaflet thrombosis, and ultimately may result in leaflet degeneration in the form of fibrosis or calcification. ${ }^{12}$ An interruption of antithrombotic therapy also may be a predisposing factor. ${ }^{13}$

In this study, all 11 patients who underwent reoperation due to SVD were prescribed antiplatelet therapy at hospital discharge without receiving oral anticoagulation therapy postoperatively. Although data from the Danish National Patient Registry support a benefit of using anticoagulation during the first 6 months after bioprosthetic aortic valve replacement, there is discordance regarding this information between the European and American College of Cardiology/American Heart Association guidelines. ${ }^{12,14}$ It remains uncertain whether a period of more intensive antithrombotic therapy postoperatively may result in fewer cases of early SVD.

The Trifecta valve was shown to have excellent hemodynamic performance both at rest and during exercise through the first year postimplant. ${ }^{15-17}$ The excellent hemodynamic performance has been shown to persist through 3-years of follow-up, ${ }^{18}$ and with this mid-term follow-up study the results are extended to 6 years of follow-up. Hemodynamic performance becomes most clinically relevant when a small aortic root is encountered and a decision is made to implant a small valve size without enlarging the aortic root. In this study at 5 years postimplant, the mean transvalvular gradients for the $19-\mathrm{mm}$ and 21-mm Trifecta valve sizes were 14.3 and $10.5 \mathrm{~mm} \mathrm{Hg}$, respectively. In comparison, Banbury and colleagues ${ }^{9}$ report at 5-years postimplant mean transvalvular gradients of 18 and $14 \mathrm{~mm} \mathrm{Hg}$ for the $19 \mathrm{~mm}$ and $21 \mathrm{~mm}$ sizes of the Carpentier-Edwards PERIMOUNT valve (Edwards Lifesciences, Irvine, Calif), respectively. Several recent studies have shown that the Trifecta valve has improved hemodynamic performance compared with the Carpentier-Edwards PERIMOUNT Magna Ease valve (Edwards Lifesciences) both at rest and during exercise, ${ }^{15-19}$ and in one study involving patients with left ventricular hypertrophy there was greater regression of left ventricular mass in patients implanted with the Trifecta valve. ${ }^{19}$ The excellent hemodynamic performance of the Trifecta valve reduces the likelihood of developing patient-prosthesis mismatch, which is of clinical significance because patient-prosthesis mismatch has been shown to be associated with an increase in mortality and a reduction in freedom from SVD. ${ }^{20,21}$ 
The excellent hemodynamic performance of the Trifecta valve is achieved as a result of a valve design that allows for more complete opening of the valve using leaflets that are mounted externally onto a thin flexible titanium stent frame. Because of the excellent hemodynamic performance of the Trifecta valve, oversizing of the valve usually is not necessary to achieve the desired hemodynamic performance. ${ }^{16}$ Although previous clinical experience with older generations of pericardial tissue valves that use an alignment stitch at the top of externally mounted leaflets have encountered challenges with respect to early failures, ${ }^{22}$ this study demonstrates that the Trifecta valve remains durable through 6 years of follow-up. There is no alignment stitch in the design of the Trifecta valve and in vitro testing demonstrates by means of accelerated lifetime cyclic testing a fully functional valve after 1.25 billion cycles (approximately 31 years). ${ }^{23}$ The primary mode of SVD observed in vivo in this study was fibrous thickening of the leaflets or calcific leaflet degeneration, but the observed rate was low. The observed freedom from reoperation due to SVD at 6 years of follow-up for the Trifecta valve was $97.3 \%$. This finding compares favorably with the freedom from reoperation due to SVD observed for the CE PERIMOUNT valve, which was reported to be $97.2 \%$ at 7 years postimplant. ${ }^{24}$ The primary mode of failure reported for the CE PERIMOUNT valve also was fibrous-calcific leaflet deterioration.

Both the Trifecta valve and the CE PERIMOUNT valve have anticalcification treatment that reduces the likelihood of developing fibrous-calcific SVD; however, in comparison, earlier generations of the Mitroflow valve (Models 12A and LX; SORIN Group, Milan, Italy) do not have anticalcification treatment, thereby increasing the potential for early calcific leaflet deterioration. ${ }^{10}$ When the Mitroflow Model 12A valve was used, the freedom from reoperation caused by SVD was reported by Asch and colleagues ${ }^{25}$ to be $97.8 \%$ at 5-years post-implant. The primary failure mode reported for the Mitroflow valve was calcific deterioration. ${ }^{11}$

The evolution over time of hemodynamic parameters for the Trifecta valve demonstrates a slight increase in the percentage of valves with mild-to-severe aortic regurgitation. This is an expected finding, considering that some of the valves may develop leaflet thickening which can impact leaflet coaptation. A similar increase in the percent of valves with mild to severe aortic regurgitation is observed for the CE PERIMOUNT valve. ${ }^{9}$ When we used the mixed model, the estimated percentages of Trifecta valves with mild, moderate, and severe aortic regurgitation at 6 years postimplant were $13.7 \%, 4.7 \%$, and $2.7 \%$, respectively. In comparison, the CE PERIMOUNT valve has estimated percentages of mild, moderate, and severe aortic regurgitation at 6 years postimplant of $24.0 \%, 9.7 \%$, and $2.9 \%$, respectively. ${ }^{9}$

All reoperations for SVD in this study were performed with an open surgical approach rather than via a transcatheter valve-in-valve implantation procedure. The feasibility of being able to perform with a good outcome a valve-in-valve transcatheter aortic valve replacement (TAVR) in a 23-mm Trifecta valve has been demonstrated previously. ${ }^{26}$ The procedure was performed without causing coronary artery obstruction despite having the leaflets mounted externally on the stent.

When contemplating TAVR as an alternative to primary surgical aortic valve replacement, it is important to keep in mind that surgically implanted aortic valves have a lower incidence of aortic regurgitation, and in particular a lower incidence of paravalvular aortic regurgitation. ${ }^{27-29}$ The freedom from paravalvular leak for the Trifecta valve was $98.9 \%$ at 6 years of follow-up. In addition, the need for a postoperative permanent pacemaker is greater when performing TAVR compared with surgical aortic valve replacement. In this study for comparison, $6.1 \%$ of patients required a new permanent pacemaker implant within 30 days postoperatively. ${ }^{28,29}$ There are limited data available for comparison on the freedom from reoperation due to SVD in patients undergoing TAVR. ${ }^{30}$ The 5-year data for the Edwards SAPIEN transcatheter aortic valve (Edwards Lifesciences) from the PARTNER 1 study show no cases of SVD requiring reoperation. ${ }^{31}$ In comparison, the freedom from reoperation due to SVD for the Trifecta valve at 5 years was $99.2 \%$; however, the patients in the PARTNER 1 study were older with an age of $83.6 \pm 6.8$ years.

\section{Study Limitations}

This study is limited because not all patients enrolled in the premarket study agreed to participate in longer-term follow-up. After closure of the premarket study there were 176 patients $(24.8 \%)$ who declined longer-term follow-up. In addition, echocardiograms at 4 years and 6 years postimplant were not required for patients enrolled in the long-term follow-up study (NCT01593917). Although not all patients agreed to participate in longer term follow-up, there are a substantial number of patients with echocardiogram data available for analysis, making the results of this study meaningful.

\section{CONCLUSIONS}

This study demonstrates that the Trifecta valve has excellent hemodynamic performance, particularly in the smaller valve sizes, that is maintained through 6 years of follow-up. The study also demonstrates that the Trifecta valve has a low complication rate and exhibits excellent durability over 6 years of follow-up. Cardiac surgeons performing aortic valve replacement should be aware of 
these findings, particularly when confronted with a small aortic root.

\section{Webcast}

You can watch a Webcast of this AATS meeting presentation by going to: http://webcast.aats.org/2016/Video/Wednesday/ 05-18-16_Ballroom_I_0803_Goldman-800.mp4.

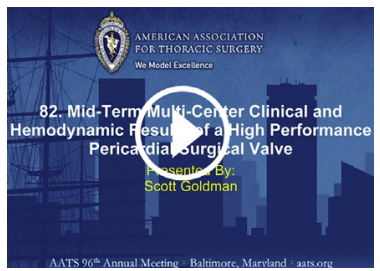

\section{Conflict of Interest Statement}

Scott Goldman, MD, is a consultant to St Jude Medical, Edwards Lifesciences, LSI, and Abbott. Anson Cheung, MD, is a consultant to St Jude Medical. Joseph E. Bavaria, MD, is a St Jude Medical Principal Investigator for Trifecta valve trial, Edwards Lifesciences Principal Investigator for PARTNER trial, Medtronic Principal Investigator for SURTAVI trial, Sorin Co-Principal Investigator for Perceval valve trial, Boston Scientific Sub-Principal Investigator, and Steering Committee member of Lotus valve trial. Mark A. Groh, MD, is a consultant to St Jude Medical, Edwards Lifesciences, and Atricure. Hartzell V. Schaff, MD, is a St Jude Medical Principal Investigator for Trifecta valve trial. All other authors have nothing to disclose with regard to commercial support.

The authors thank Dan Gutfinger, MD, and Hongfei Guo, PhD, from St Jude Medical in St Paul, Minnesota, and Manya Harsch, MS Principal Statistician from Technomics Research, LLC in Minneapolis, Minnesota, for assistance with the article.

\section{References}

1. Isaacs AJ, Shuhaiber J, Salemi A, Isom OW, Sedrakyan A. National trends in utilization and in-hospital outcomes of mechanical versus bioprosthetic aortic valve replacements. J Thorac Cardiovasc Surg. 2015;149:1262-9.

2. Bavaria JE, Desai ND, Cheung A, Petracek MR, Groh MA, Borger MA, et al. The St Jude Medical Trifecta aortic pericardial valve: results from a global, multicenter, prospective clinical study. J Thorac Cardiovasc Surg. 2014;147:590-7.

3. Vyavahare N, Hirsch D, Lerner E, Baskin JZ, Schoen FJ, Bianco R, et al. Prevention of bioprosthetic heart valve calcification by ethanol preincubation: efficacy and mechanisms. Circulation. 1997;95:479-88.

4. Akins CW, Miller DC, Turina MI, Kouchoukos NT, Blackstone EH, Grunkemeier GL, et al. Guidelines for reporting mortality and morbidity after cardiac valve interventions. Eur J Cardiothorac Surg. 2008:33:523-8.

5. Diggle PJ, Heagerty P, Liang K-Y, Zeger SL. Analysis of Longitudinal Data. 2nd ed. New York: Oxford University Press; 2002.

6. Hedeker D, Gibbons RD. Longitudinal Data Analysis. New York: John Wiley \& Sons; 2006.

7. Blackstone EH. Breaking down barriers: helpful breakthrough statistical methods you need to understand better. J Thorac Cardiovasc Surg. 2001;122:430-9.

8. Johnston DR, Soltesz EG, Vakil N, Rajeswaran J, Roselli EE, Sabik JF III, et al. Long-term durability of bioprosthetic aortic valves: implications from 12,569 implants. Ann Thorac Surg. 2015;99:1239-47.
9. Banbury MK, Cosgrove DM III, Thomas JD, Blackstone EH, Rajeswaran J, Okies JE, et al. Hemodynamic stability during 17 years of the CarpentierEdwards aortic pericardial bioprosthesis. Ann Thorac Surg. 2002;73:1460-5.

10. Sénage T, Le Tourneau T, Foucher Y, Pattier S, Cueff C, Michel M, et al. Early structural valve deterioration of Mitroflow aortic bioprosthesis: mode, incidence, and impact on outcome in a large cohort of patients. Circulation. 2014;130: 2012-20.

11. Alvarez JR, Sierra J, Vega M, Adrio B, Martinez-Comendador J, Gude F, et al. Early calcification of the aortic Mitroflow pericardial bioprosthesis in the elderly. Interact Cardiovasc Thorac Surg. 2009;9:842-6.

12. Egbe AC, Pislaru SV, Pellikka PA, Poterucha JT, Schaff HV, Maleszewski JJ, et al. Bioprosthetic valve thrombosis versus structural failure: clinical and echocardiographic predictors. J Am Coll Cardiol. 2015;66:2285-94.

13. Cremer PC, Rodriguez LL, Griffin BP, Tan C, Rodriguez R, Johnston DR, et al Early bioprosthetic valve failure: a pictorial review of rare causes. JACC Cardiovasc Imaging. 2015;8:737-40

14. Mérie C, Køber L, Olsen PS, Andersson C, Gislason G, Jensen JS, et al Association of warfarin therapy duration after bioprosthetic aortic valve replacement with risk of mortality, thromboembolic complications, and bleeding. JAMA. 2012;308:2118-25.

15. Collia A, Marchetto G, Salizzoni S, Rinaldi M, Di Marco L, Pacini D, et al. The TRIBECA study: (TRI)fecta (B)ioprosthesis (E)valuation vs (C)arpentier Magna-Ease in (A)ortic position. Eur J Cardiothorac Surg. 2015;49:478-85.

16. Domoto S, Niinami H, Uwabe K, Koike H, Tabata M, Morita K, et al. Comparison of early haemodynamics of 19-mm aortic valve bioprostheses in patients with a small aortic annulus. Interact Cardiovasc Thorac Surg. 2016;22:19-25.

17. Bach DS, Patel HJ, Kolias TJ, Deeb GM. Randomized comparison of exercise haemodynamics of Freestyle, Magna Ease and Trifecta bioprostheses after aortic valve replacement for severe aortic stenosis. Eur J Cardiothorac Surg. 2016;50:361-7.

18. Ruggieri VG, Anselmi A, Chabanne C, Lelong B, Flecher E, Verhoye J-P, et al Three-year haemodynamic performance of the St Jude Trifecta bioprosthesis. Eur J Cardiothorac Surg. 2016;49:972-7.

19. Rubens FD, Gee Y-Y, Ngu JMC, Chen L, Burwash IG. Impact of aortic pericardial valve choice on outcomes and left ventricular mass regression in patients with left ventricular hypertrophy. J Thorac Cardiovasc Surg. 2016;152:1291-8.e2.

20. Head SJ, Mokhles MM, Osnabrugge RLJ, Pibarot P, Mack MJ, Takkenberg JJM, et al. The impact of prosthesis-patient mismatch on long-term survival after aortic valve replacement: a systematic review and meta-analysis of 34 observational studies comprising 27,186 patients with 133,141 patient-years. Eur Heart J. 2012;33:1518-29.

21. Flameng W, Rega F, Vercalsteren M, Herijgers P, Meuris B. Antimineralization treatment and patient-prosthesis mismatch are major determinants of the onset and incidence of structural valve degeneration in bioprosthetic heart valves. J Thorac Cardiovasc Surg. 2014;147:1219-24.

22. Singhal P, Luk A, Butany J. Bioprosthetic heart valves: impact of implantation on biomaterials. ISRN Biomaterials. 2013;2013:728791.

23. Smoczyński R, Sarnowski W, Kłapyta A, Szafron B, Kosior D, Sypuła S, et al. Early experience with implantation of the new biological Trifecta valve. Kardiochirurgia i Torakochirurgia Polska. 2013;10-2:105-9.

24. Frater RWM, Salomon NW, Rainer WG, Cosgrove DM III, Wickham E. The Carpentier-Edwards pericardial aortic valve: intermediate results. Ann Thorac Surg. 1992;53:764-71.

25. Asch FM, Heimansohn D, Doyle D, Dembitsky W, Ferdinand FD, Swanson J Mitroflow aortic bioprosthesis 5-year follow-up: North American prospective multicenter study. Ann Thorac Surg. 2012;94:1198-203.

26. Kim W-K, Kempfert J, Walther T, Mollmann H. Transfemoral valve-in-valve implantation of a St. Jude Medical Portico in a failing Trifecta bioprosthesis: a case report. Clin Res Cardiol. 2015;104:363-5.

27. Hahn RT, Pibarot P, Stewart WJ, Weissman NJ, Gopalakrishnan D, Keane MG, et al. Comparison of transcatheter and surgical aortic valve replacement in severe aortic stenosis: a longitudinal study of echo parameters in cohort A of the PARTNER trial. J Am Coll Cardiol. 2013;61:2514-21.

28. Holmes DR Jr, Nishimura RA, Grover FL, Brindis RG, Carroll JD, Edwards FH, et al. Annual outcomes with transcatheter valve therapy: from the STS/ACC TVT Registry. Ann Thorac Surg. 2015;101:789-800.

29. Thourani VH, Kodali S, Makkar RR, Herrmann HC, Williams M, Babaliaros V, et al. Transcatheter aortic valve replacement versus surgical valve replacement in intermediate-risk patients: a propensity score analysis. Lancet. 2016;387: 2218-25.

30. Arsalan M, Walther T. Durability of prostheses for transcatheter aortic valve implantation. Nat Rev Cardiol. 2016;13:360-7. 
31. Mack MJ, Leon MB, Smith CR, Miller DC, Moses JW, Tuzcu EM, et al. 5-year outcomes of transcatheter aortic valve replacement or surgical aortic valve replacement for high surgical risk patients with aortic stenosis (PARTNER 1): a randomised controlled trial. Lancet. 2015;385:2477-84.

Key Words: aortic valve replacement, bioprosthesis, gradient, durability

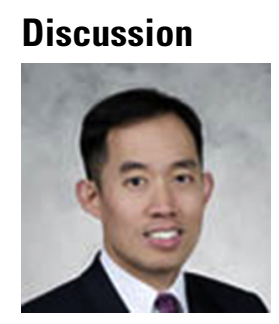

Dr J. Woo (Stanford, Calif). I congratulate you and your coauthors on your continued longitudinal assessment of the performance of this valve. Via this report and other published studies, including a randomized trial, it appears there may be substantive hemodynamic benefits with this valve, particularly in the smaller sizes.

I have 3 brief questions. There have been a series of reports published on early structural valve failure of another externally wrapped pericardial valve. Do you or any of your coauthors have any concerns about the long-term durability of this valve design?

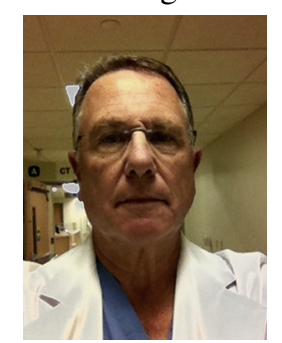

Dr Goldman. I understand that there have been reports of that valve. I think there are some features of this valve that are different in that the pericardium does have an anticalcification treatment, which is absent in the other valve, and I think that some structural deterioration may be related to the calcification, which could weaken the tissue. Also, the stents are covered in porcine pericardium, which may decrease abrasion, which also could cause structural failure.

Again, I think we all have concerns about long-term durability of all these valves, and we won't know until we have further data.

Dr Woo. The mean gradients appear to increase over time in several of the sizes. Do you have any qualitative echocardiographic data on which you might wish to elaborate?

Dr Goldman. No. The echo just showed slight increases over time. This has been reported with other pericardial valves, particularly, Banbury reported this with the Perimount valve. The pericardium does stiffen up over time, but it seems like it is not clinically significant.

Dr Woo. Finally, would you care to comment on potential limitations of this valve with its angled strut design and external wrapping with respect to future potential transcatheter valve-in-valve replacement?

Dr Goldman. We have done some valve-in-valves with this valve without having any issues with coronary obstruction, although when you put this valve in and you see it opening and it goes all the way out to the sinotubular ridge, you may have some concern with that. Again, there haven't been that many valve-in-valves with this valve, so we will have to see how it goes. But I think it could be a potential issue. 


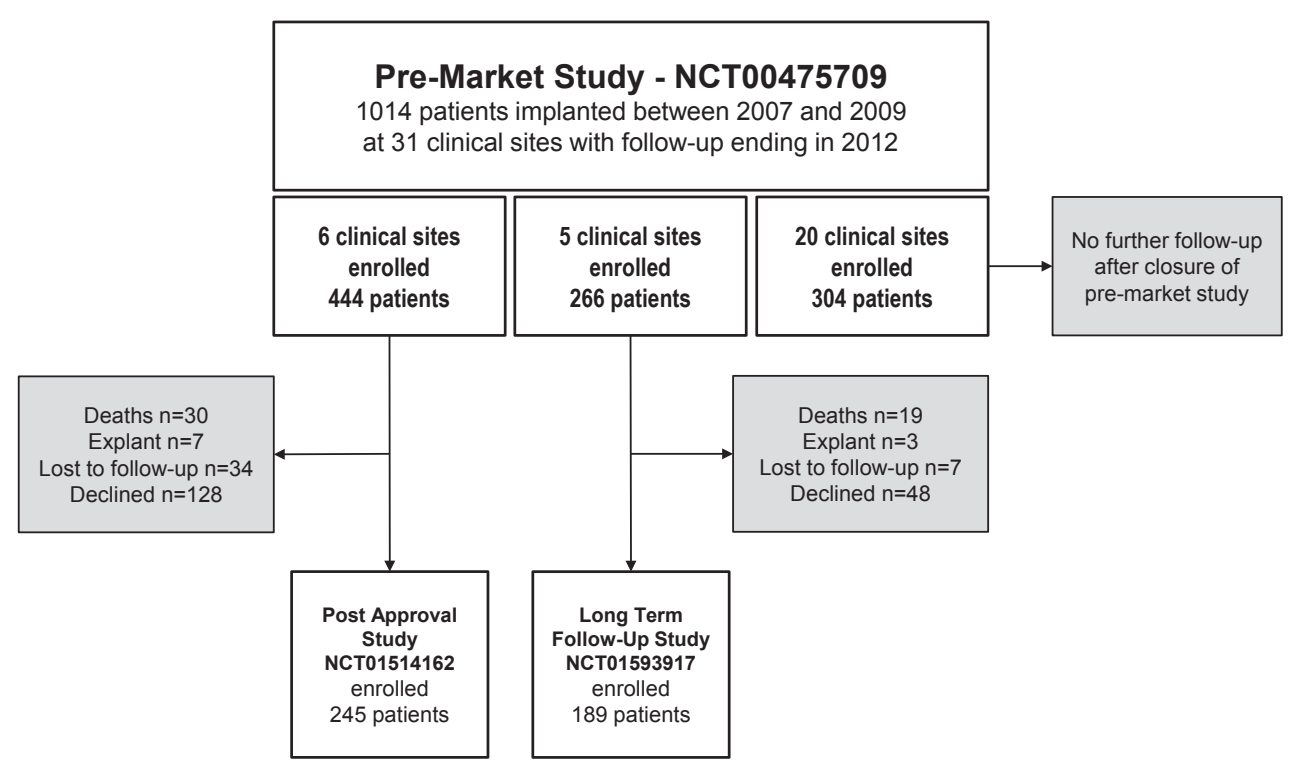

FIGURE E1. Premarket to postmarket study flow.

TABLE E1. Change over time in hemodynamic measurements (linear mixed model)

\begin{tabular}{lcc}
\hline \multicolumn{1}{c}{ Correlates } & Regression coefficient \pm SE & $\boldsymbol{P}$ value \\
\hline Mean gradient, $\mathrm{mm} \mathrm{Hg}^{*}$ & & \\
Shorter implant duration, $\mathrm{y} \dagger$ & $-0.35 \pm 0.023$ & $<.0001$ \\
Smaller valve size, $\mathrm{mm} \ddagger$ & $1.57 \pm 0.12$ & $<.0001$ \\
Intercept & $0.78 \pm 0.14$ & $<.0001$ \\
Effective orifice area, $\mathrm{cm}^{2 *}$ & & \\
$\quad$ Shorter implant duration, $\mathrm{y} \dagger$ & $0.24 \pm 0.010$ & $<.0001$ \\
Smaller valve size, $\mathrm{mm} \ddagger$ & $-1.16 \pm 0.047$ & $<.0001$ \\
Intercept & $1.44 \pm 0.055$ & $<.0001$ \\
Effective orifice area index, $\mathrm{cm}^{2} / \mathrm{m}^{2 *}$ & & \\
Shorter implant duration, $\mathrm{y}^{\dagger}$ & $0.23 \pm 0.010$ & $<.0001$ \\
Smaller valve size, $\mathrm{mm} \ddagger$ & $-0.54 \pm 0.057$ & $<.0001$ \\
Intercept & $0.086 \pm 0.066$ & $<.0001$ \\
\hline
\end{tabular}

$S E$, Standard error. *Logarithmic transformation. †10/(implant duration +5$)$, inverse transformation. $₫ 25 / v a l v e$ size, inverse transformation.
TABLE E2. Change over time in NHYA class and aortic regurgitation grade (ordinal longitudinal mixed model)

\begin{tabular}{lcc}
\hline \multicolumn{1}{c}{ Correlates } & Regression coefficient \pm SE & $\boldsymbol{P}$ value \\
\hline NYHA class & & \\
$\quad$ Implant duration, y & $0.13 \pm 0.044$ & $<.0001$ \\
Intercept 1 & $3.34 \pm 0.21$ & $<.0001$ \\
Intercept 2 & $6.34 \pm 0.29$ & $<.0001$ \\
Aortic regurgitation grade & & \\
Implant duration, y & $0.69 \pm 0.065$ & $<.0001$ \\
Intercept 1 & $7.52 \pm 0.53$ & $<.0001$ \\
Intercept 2 & $10.60 \pm 0.64$ & $<.0001$ \\
Intercept 3 & $12.33 \pm 0.78$ & $<.0001$ \\
\hline
\end{tabular}

SE, Standard error; NYHA, New York Heart Association. 
APPENDIX E1. Study inclusion and exclusion criteria

\section{Inclusion criteria}

1. Patient requires aortic valve replacement. Patients undergoing concomitant procedures, such as coronary artery bypass grafting or valve repair are eligible for the study.

2. Patient is of legal age in host country.

3. Patient (or legal guardian) has given written informed consent for participation before surgery.

4. Patient is willing to undergo all study procedures and adhere to all data collection and follow-up requirements.

\section{Exclusion criteria}

1. Patient is pregnant or nursing. Women of child-bearing potential must have a documented negative pregnancy test within $1 \mathrm{wk}$ before surgery.

2. Patient already has a prosthetic valve(s) at a site other than the aortic valve.

3. Patient requires concomitant replacement of the tricuspid, pulmonary, or mitral valve.

4. Patient has an inability or is unwilling to return for follow-up visits.

5. Patient has active endocarditis. Patients with previous endocarditis must have 2 documented negative blood culture results before enrollment.

6. Patient has had an acute preoperative neurologic event defined as follows: patient has not returned to baseline or has not stabilized $30 \mathrm{~d}$ before the planned valve implantation surgery.

7. Patient is undergoing renal dialysis.

8. Patient has a documented history of substance abuse within $1 \mathrm{y}$ of enrollment, or is currently a prison inmate.

9. Patient currently is participating in the study of an investigational drug or device, or the patient was previously participating in an investigational drug study and has not completed a 30-d washout period.

10. Patient had the Trifecta valve implanted as part of this study but then had the device explanted.

11. Preoperative evaluation indicates other significant cardiovascular abnormalities such as aortic dissection or ventricular aneurysm.

12. Patient has a life expectancy less than $2 \mathrm{y}$.

APPENDIX E2. Principal Investigator list

\begin{tabular}{ll}
\hline Principal investigator & \multicolumn{1}{c}{ Investigational site } \\
\hline Hartzell Schaff, MD & Mayo Clinic \\
Joseph Bavaria, MD & Hospital of the University of Pennsylvania \\
Vibhu Kshettry, MD & Abbott Northwestern Hospital \\
Mark Groh, MD & Mission Health \& Hospitals \\
Michael Petracek, MD & Vanderbilt University Medical Center \\
Kent Jones, MD & Intermountain Medical Center \\
A. Marc Gillinov, MD & Cleveland Clinic Foundation \\
Scott Goldman, MD & Lankenau Hospital \\
Vaughn Starnes, MD & University of Southern California \\
Anson Cheung, MD & St. Paul's Hospital-University of British Columbia \\
Eric Charbonneau, MD & Institut de Cardiologie de Quebec (Hopital Laval) \\
\hline
\end{tabular}

